\title{
Exposure Assessment of Pharmaceuticals and Their Metabolites in the Aquatic Environment: Application to the French Situation and Preliminary Prioritization \\ Besse, J.P., Kausch Barreto, C., Garric, J.
}

\section{$\underline{\text { ABSTRACT }}$}

Low levels of pharmaceuticals have been detected in many countries in surface waters. As a wide range of pharmaceuticals can reach aquatic environments, a selection of molecules to survey is the first step before implementing a monitoring program. We used a simple equation to calculate Predicted Environmental Concentrations (PECs), adapted from the European Medicine Agency model used for the Environmental Risk Assessment (ERA) of human pharmaceutical. Excretion fractions for pharmaceuticals were determined for 76 compounds. Using year 2004 French drug consumption data, we determined aquatic PECs for 112 parent molecules and several metabolites. Considering excretion fractions of pharmaceuticals can lead to drastically reduce predicted concentrations reaching the aquatic environment and help to target environmentally relevant pharmaceuticals and metabolites. Calculated PECs using the described methodology are consistent with French field measurements. The simple model for calculating PECs can be used as a valuable estimation of the exposure. Risk quotient ratios were also calculated. Due to the lack of ecotoxicological data, the use of PEC/PNEC ratios is not enough informative to prioritize pharmaceuticals likely to pose a risk for surface waters. Alternative ways to prioritize risk to pharmaceuticals, combining PEC, pharmacological, and ecotoxicological data available from the literature, should be implemented.

\section{INTRODUCTION}

It is now recognized that pharmaceutical compounds reach the environment and can be considered as environmental contaminants. A wide range of drugs including antibiotics, antidepressants, non steroidal anti-inflammatories (NSAIDs), blood lipid-lowering agents, antiepileptics, and $\beta$-blockers have been found in wastewater effluents and surface waters of several countries (Halling-Sorensen et al. 1998; Ternes 1998; Kümmerer 2000; Kolpin et al. 2002). These observations have contributed to a growing interest in targeting and quantifying these substances in terrestrial and aquatic environments. In France, there is a concern for monitoring pharmaceuticals in freshwaters as this country shows the highest consumption of pharmaceutical drugs in Europe (DREES 2006). This concern is addressed in the framework of the French Plan National Santé Environnement (PNSE 2004) and in Europe, in the context of preventing deterioration and protecting and enhancing the status of aquatic ecosystems, within the European Water Framework Directive. River basin authorities therefore need to establish a list of priority pharmaceuticals prior to implementing a comprehensive survey in surface waters. In this aim, we developed a prioritization approach to identify human pharmaceuticals to be monitored in French surface waters. As a first step in this prioritization strategy, we used a simple equation to calculate Predicted Environmental Concentrations (PECs) adapted from the model proposed by the European Medicine Agency (EMEA) guideline (EMEA 2006). This equation takes into account three main parameters: the amount of active ingredients consumed by the population over a year, the removal fraction in wastewater treatment plants (WWTPs), and the excretion fraction of the active molecule. Pharmaceuticals enter surface waters mainly from WWTPs 
(Kümmerer 2000, 2001; Bound and Voulvoulis 2004). The majority of human pharmaceuticals probably reach surface waters after being excreted from the body, either as parent compounds or metabolites. Consequently, we reviewed metabolism data in order to estimate values of the excreted fraction of pharmaceuticals. We also targeted metabolites that present significant pharmacological activity and can be found in the environment in non-negligible concentrations. Our study focused on the most widely used human pharmaceuticals in France. We excluded steroid estrogens from this work, as the risk of endocrine disruption has been previously discussed (Langston et al. 2005; Mills and Chichester 2005; Fent et al. 2006). Cytotoxic compounds were also excluded because these drugs have specific toxic properties (mutagenesis and carcinogenicity), and need to be assessed in a specific prioritization approach. PECs for parent compounds and metabolites were calculated using the methodology presented here and were compared with field measurements. Next, the reliability of the applied methodology was discussed. Finally, we determined risk quotient ratios, according to the EMEA guideline. Results and use of the PEC/PNEC (Predicted No Effect Concentration) risk quotient for prioritizing and ranking pharmaceuticals are discussed.

\section{MATERIALS AND METHODS}

\section{I.1. Model Used for Calculating PECs}

The EMEA guideline (EMEA 2006) proposes an approach to estimate PEC values for pharmaceuticals in surface water. PECs are calculated by using the following general equation:

$$
\text { PECsurface water }=\frac{\text { ELOCALwat } \times \text { Fstp }}{\text { WWinhab } \times \text { CAPstp } \times \text { Factor } \times \text { Dilution }}
$$

with:

$$
\text { ELOCALwat }=\text { DOSEai } \times \text { Fexcreta } \times \text { Fpen } \times \text { CAPstp }
$$

and

$$
\text { Fpen }=\frac{\text { consumption } \times 100}{D D D \times h a b \times 365}(3)
$$

where PEC is expressed in mg.1-1 using the following parameters: consumption is the quantity (mg.year-1) of an active molecule consumed by the population during 1 year in a defined zone (generally a country); $h a b$ is the number of inhabitants and 100 the correction factor for the percentages; 365 is the number of days per year (day-year-1); DOSEai: maximum recommended daily dose of an active molecule consumed per inhabitant (mg. inhabitants-1 day-1); DDD: Defined Daily Dose for an active molecule (mg. inhabitants-1 day-1); WWinhab: volume of wastewater per person per day (default value $=2001$. inhabitants-1 day-1); CAPstp: capacity of local sewage treatment plant (inhabitants); dilution is the dilution factor from WWTP effluent to surface waters (default value set to 10). Factor stands for the fraction of the molecule adsorbed to the suspended matter; Fpen (\%): market penetration factor; Fpen is the proportion of the population being treated daily with a specific drug substance; Fexcreta: excretion fraction of the active molecule; Fstp: fraction of emission of the drug from wastewater treatment plants (WWTP) directed to surface water, Fstp can be defined as (1-WWTP removal fraction). Combination of Eqs. (1), (2), and (3) gives the following: 


$$
\text { PECsurfacewater }=\frac{\text { consumption } \times \text { Fexcreta } \times \text { Fstp } \times \text { DOSEai } \times 100}{\text { WWinhab } \times \text { hab } \times \text { Factor } \times \text { Dilution } \times D D D \times 365}
$$

In the aim of our prioritization strategy, we simplified this last equation. Eq. (4) is finally transformed into Eq. (5) as follows:

$$
\text { PECsurfacewater }=\frac{\text { consumption } \times \text { Fexcreta } \times \text { Fstp }}{\text { WWinhab } \times \text { hab } \times \text { Dilution } \times 365}
$$

all PEC calculations presented in this study will refer to Eq. (5).

\section{I.2. Consumption Data Sources}

The French medicine agency (Agence Française de Sécurité Sanitaire des Produits de Santé, AFSSAPS, Paris) kindly shared yearly sales data compulsory provided by the pharmaceutical firms to AFSSAPS. These data cover both sale quantities of all prescribed drugs delivered in France and over-the-counter drugs for the year 2004 for hospitals and pharmacies. In the scope of this work we assume that delivered quantities represent quantities effectively consumed by the French population and that the consumed amount was evenly distributed throughout the year, as assumed in Carlsson et al. (2006). The candidate list of pharmaceuticals was established as follows: a first set of molecules was selected from the top 100 pharmaceuticals used in France (AFSSAPS 2006). To this first set of molecules, we added those that were reported in previous studies to be detected in the aquatic environment or to be of high aquatic ecotoxicity, and finally the molecules known to be persistent in the environment. The list of selected molecules is displayed in Table 1; compounds are sorted by decreasing consumption. As discussed in the introduction, neither steroid estrogens nor cytotoxics were included in this set of molecules.

\section{I.3. Determination of the Parameter Fexcreta}

\section{Implications of Pharmaceutical Metabolism for Environmental Considerations}

In the human body, active molecules pass through several biotransformation mechanisms ending in their elimination from the organism. Schematically, biotransformations can be summarized into two different steps: phase I and phase II biotransformations. Phase I metabolites can show a pharmacological activity similar or not to the parent compound and be biologically active. As an example, norfluoxetine, a phase I metabolite of the serotoninergic antidepressant fluoxetine, shows the same pharmacological activity as the parent compound. Phase II metabolites are phase I metabolite or parent compound conjugated with a functional group (such as glucuronide, sulphate, or acetate), which enhance elimination from the organism and inactivate the molecule. It has been shown for estrogens that glucuronide phase II metabolites could be cleaved in the environment and thus regenerate the parent compound (Ternes et al. 1999; D'Ascenzo et al. 2003). Moreover, sulphate conjugates appear to be more stable in the environment (D'Ascenzo et al. 2003). As shown for estrogens, we can reasonably assume that 
glucuronide conjugates of pharmaceutical compounds are subjected to the same degradation pathway and are cleaved in the environment. Therefore, active metabolites and glucuronide conjugates have to be considered in an Environmental Risk Assessment (ERA) or a prioritization approach.

\section{Fexcreta Calculation}

To provide reasonable Fexcreta values, we made the following assumptions: We assumed that all glucuronide conjugates are cleaved in the environment. Consequently, Fexcreta was determined by summing the excreted proportion of the unchanged active molecule (in urine and/or in feces) and the proportion of the parent molecule existing as a glucuronide conjugate. If no information was given on the nature of the conjugate, we assumed a worst case hypothesis considering that all conjugates were glucuronide conjugates. Rates of molecule not absorbed by the digestive tract were added to the other excretion rates to give the final Fexcreta value. Modifications in metabolism rates that can occur in unhealthy people were not taken into account. When more than one excretion value was given, we always chose the greater one, assuming a worst case scenario (decimal values were rounded up or down to the nearest value). When information such as "negligible excretion of unchanged drug" was given with no other specific information, we assumed a Fexcreta value minimum of 0.01 . When no reliable data were found, no Fexcreta value was calculated. Finally, when data were available, we calculated the Fexcreta value for active metabolites using the same methodology with the assumptions described earlier. The methodology used to determine Fexcreta values is synthesized in Figure 1.

\section{I.4. Reference Books and Databases Reviewed}

In order to determine metabolism pathways of selected pharmaceuticals and to calculate Fexcreta values, we reviewed data from several sources commonly used by healthcare services (hospitals, pharmacovigilance services, pharmacists, etc.): the Banque Claude Bernard (BCB 2006), a complete and free French databank on human pharmaceuticals (http://www.resip.fr), the $\mathrm{BCB}$ is updated monthly, notably with data from the Marketing Authorisation Application (MAA); the BIAM database (www.biam2.org 2006); the drug database drugs.com (www.drugs.com); the Micromedex Drugdex_R databank (from Thomson Micromedex, available at www.micromedex.com/products/drugdex); the Martindale compendium's Complete Drug Reference (Martindale 2002); the Goodman \& Gilman's The Pharmacological Basis of Therapeutic (Hardman et al. 1996); the Merck Index (Merck 2001); and the Dorosz Guide pratique des m'edicaments (Dorosz 2007). The HSDB database (http://www.toxnet. nlm.nih.gov/) was also investigated.

\section{RESULTS}

\section{II.1. Excretion Factor Values}

Excretion factor values are displayed in Table 1. Reviewing the databases allowed us to determine Fexcreta values for 76 molecules of the 112 selected. From the 76 compounds for which Fexcreta values were determined, 45 showed excretion rates less than 0.5 and 23 compounds present excretion rates less than 0.1. Although the data determined here are consistent 
with previous published excretion rates, some differences can be noted for a few of the

178 compounds studied. We report an excretion value for sulfamethoxazole of 0.4 compared to 0.15

179 (Ternes 1998) and 0.25 versus 0.01-0.08 for ibuprofen (Ternes 1998). In the case of ibuprofen,

180 this difference can be explained by the fact that the proportion of glucuronide conjugates was

181 added in our study. For furosemide, in taking into account the glucuronide ester metabolites, we

182 calculated a Fexcreta value of 1 instead of the value of 0.4 reported by Bindschedler et al. (1997).

183 As the glucuronide ester is reported to be the only significant metabolite of furosemide

184 (Micromedex Drugdex_R 2006), we considered that all furosemide was excreted unchanged or as

185 glucuronide metabolite, with $100 \%$ of the dose excreted in the environment after cleavage of the

186 ester. Hirsch et al. (1999) reported excretion fractions for antibiotics. Our results are in good

187 agreement with these values for doxycycline, amoxicillin, trimethoprim, and erythromycin; for

188 erythromycin, we assumed a worst case value of 1 . On the contrary, for roxithromycin and

189 clarithromycin, the results differ significantly. Hirsch reports excretion rates of both unchanged

190 molecules greater than 0.6 , whereas we determined a 0.5 value for roxithromycin and a 0.3 value

191 for clarithromycin. For carbamazepine, a Fexcreta of about 0.01 to 0.03 was reviewed from the

192 literature (Ternes 1998; Jjemba 2006), which corresponds to the unchanged fraction excreted in

193 urine. However, carbamazepine is also excreted in faeces and can be metabolized in glucuronide

194

195

196

197

198

199

200

201

202

203

204

205

206

207

208

209

210

211

212

213

214

215

216

217

218

219

220

221

222

223

conjugates (Lynn et al. 1978; BCB; Micromedex Drugdex 2006). Nevertheless, as no quantitative data were available to allow calculating an accurate Fexcreta value, we chose to consider Fexcreta for this molecule as undetermined rather than giving a wrong estimation. For the active metabolite of simvastatin ( $\beta$-hydroxy-acid metabolite), we did not find any value in the reviewed databases. However, Carlsson et al. (2006) report that 55\% of the parent pro-drug simvastatin is excreted under the activated form. Therefore, we assumed a Fexcreta value of 0.55 for the $\beta$-hydroxy-acid metabolite in our work.

\section{II.2. Active Metabolites Entering the Aquatic Environment}

Reviewing metabolism pathways of pharmaceutical compounds allowed us to target specific metabolites that may be of potential concern for the aquatic environment. These metabolites were selected because they present either a significant pharmacological activity, or a significant excretion fraction $(\geq 0.1$, threshold value assumed by the EMEA). Metabolites of interest are listed with their excretion values and their pharmacological properties in Table 2. In addition, searching for active metabolites allowed us to highlight specific compounds that are both active molecules and metabolites. Two important drugs exemplify this particular profile: oxazepam and prednisolone. Oxazepam is an anxiolytic drug belonging to the benzodiazepine class.

Oxazepam shows a very particular profile because it is both an active molecule and a metabolite of the following active molecules: prazepam, diazepam, nordazepam, and clorazepate dipotassium (Figure 2). Prazepam, diazepam, and clorazepate are metabolized in humans to desmethyldiazepam, an active metabolite also used as a drug (nordazepam), which is subsequently transformed to oxazepam. Oxazepam then undergoes direct glucuronidation before its excretion. Glucuronide conjugates of oxazepam should then undergo subsequent cleavage in the environment and then regenerate the active oxazepam. This case is interesting because diazepam, the benzodiazepine commonly searched for in the aquatic environment, is not expected to reach surface waters in significant concentrations. Diazepam was detected at low frequency in German WWTP effluents with a maximum concentration of $40 \mathrm{ng} \cdot 1-1$ (Ternes 1998), at very low 
concentration in surface waters, less than $5 \mathrm{ng} \cdot \mathrm{l}-1$ (Fent et al. 2006) and once in drinking waters at level up to $10 \mathrm{ng} \cdot 1-1$ (Waggott et al. 1981, cited by Halling-Sorensen 1998). Nevertheless, most of the studies did not detect diazepam in effluents (Clara et al. 2005; Carballa et al. 2005; Rabiet et al. 2006) or in surface waters (Ternes 1998; Zuccato et al. 2005). On the contrary, oxazepam, which is potentially excreted up to $100 \%$ (taking into account the glucuronide conjugates) of the dose absorbed for the five different active molecules, is expected to be present at greater levels in the aquatic environment. A very recent study on occurrence of pharmaceuticals in aquatic systems in France (Togola et al. 2007) did not detect diazepam in surface waters, whereas oxazepam was measured at significant concentrations (up to 1500 ng.1-1). Therefore, we assume that oxazepam is the benzodiazepine to search for in the environment, and that this drug could be used as an indicator of contamination of the aquatic environment by benzodiazepines.

Prednisolone belongs to the glucocorticoid therapeutic class. Glucocorticoids are natural (hydrocortisone or cortisol) or synthesized (prednisolone, prednisone,

betamethasone, or dexamethasone) steroid compounds. They present immunosuppressant properties and are used in many different pathologies (inflammation, allergy, auto-immune disease, etc.). Reviewed metabolism data are incomplete but available data show that only a small portion (less than 5\%) of glucocorticoids are excreted in unchanged form (Schorderet 1998), except for prednisolone, which is excreted in a greater fraction: up to $24 \%$ in case of a large dose (Schorderet 1998; Martindale 2002). Prednisolone is also the active form of prednisone. Therefore, non-negligible levels of prednisolone can reach the environment. Consequently, prednisolone should be searched for in the environment and could be used as a marker of contamination for other glucocorticoids. This assumption is partially confirmed by the results of Chang et al. (2007), who report that prednisolone is the synthetic glucocorticoid frequently found in surface waters. These results indicate that metabolism data are useful for selecting relevant pharmaceuticals or metabolites to survey in surface waters.

\section{II.3. Calculated PECs for Parent Compounds}

PECs were calculated using Eq. (5). As all required data were not available (especially WWTP removal rates data) for all the selected molecules, three PEC values were calculated corresponding to varying conservative levels. PECA is the conservative PEC calculated with actual amounts of pharmaceuticals and not refined by Fexcreta and Fstp values. PECB are PECA refined by Fexcreta values. PECC are PECBrefined by Fstp values. Results for PECA and PECB are displayed in Table 1 . Considering PECA values, only 15 compounds show a value greater than $1 \mu \mathrm{g} \cdot 1-1$ and our results highlight paracetamol, ibuprofen, dextropropoxyphene, amoxicillin, and aspirin. PECA values of troxerutin and diosmin, two flavonoid compounds with vitamin $\mathrm{P}$ properties (used against veinous insufficiency of the lower limbs), are also in the top 10 because they are widely prescribed in France, contrary to other European countries; these last two drugs may be specific to the French consumption profile.

For compounds such as sertraline, dextropropoxyphene, omeprazole, and pantoprazole, the PECB values are drastically reduced. For example, for the antidepressant sertraline, PECA is equal to $142 \mathrm{ng} \cdot 1-1$ but drops to $20 \mathrm{ng} \cdot \mathrm{l}-1$ when excretion rates are taken into account. Comparison of PECA and PECB values confirms that metabolism is one of the most important 
processes that can reduce the quantity of parent pharmaceuticals reaching the aquatic environment.

Therefore, metabolism data and excretion rates have to be taken into account in PEC calculation (Huschek et al. 2004). As data on metabolism rates are currently available through databases, they can help to prioritize pharmaceuticals of greater concern.

\section{II.4. Comparison of PEC Values with Field Measurements}

WWTP removal rates data are limited. Reviewing literature data, we found only data for 24 molecules by the 111 selected in this work (Table 3); some of them show a high variability, depending on the study. This is especially the case for metoprolol and diclofenac with removal fractions varying from less than 0.1 to 0.83 and from less than 0.1 to 0.75 , respectively. Considering the heterogeneity of data, we determined PECC values by two methods. First, we calculated extreme PECC values by taking into account the minimal and maximal WWTP removal rates reviewed. Second, we calculated a refined PECC using theWWTP removal rates reported by Paffoni et al. (2006), as this study provides data for almost all 24 compounds. Our first objective was to compare PEC values for surface water with field measurements, but, as only few measurements of pharmaceuticals in French surface waters are available, we used data on occurrence in WWTP effluents. Consequently, in order to compare the calculated PEC with real measurements, we used Eq. (5) without the default dilution factor of 10. Calculated PECC for WWTP effluents with WWTP effluents measurements performed in France are compared in Table 4.

Calculated PECs for pharmaceuticals appear to correlate well with effluents measurements. This is the case for diclofenac, ibuprofen, naproxen, ketoprofen, bezafibrate, metoprolol, and propranolol. As a general rule, calculated PECs for antibiotics were in the range but slightly greater than the measured concentrations in effluents. For two compounds, however, PECs are very different from the effluent measurements (more than one order of magnitude); this is the case for amoxicillin and doxycycline. For amoxicillin, the difference could be explained by the fact that this molecule is rapidly degraded in water, which has been previously suggested (Zuccato et al. 2005). Another $\beta$-lactam, piperacillin, showing a PECB value for WWTP effluent of about $1 \mu \mathrm{g} \cdot 1-1$ has been searched for but not detected in WWTP effluents or surface waters in the French aquatic environment (Paffoni et al. 2006). These results suggest that $\beta$-lactam antibiotics may undergo rapid environmental degradation but this hypothesis must be confirmed. For doxycycline, previous studies have reported that tetracyclines should be bound to suspended matter and sediment due to their complexing properties (Hirsch et al. 1999). Therefore doxycycline is unlikely to be found under dissolved form but could still be in the water column if bound to suspended materials, especially colloids.

PECBs of diazepam and simvastatin (a prodrug) are very low (2 ng.l-1) and therefore those molecules were not expected to be found in effluents or surface waters, which is confirmed by field measurements (Paffoni et al. 2006; Rabiet et al. 2006). We also investigated PEC values in surface water for a few metabolites of potential concern (Table 5), considering excretion rates of metabolites and consumed amounts of the respective parent compound. Only a few of the metabolites considered in this work have already been measured in aquatic environments (but not in France), which allowed us to compare PEC and field measurements. The calculated PECB for 
acetylsulfamethoxazole is in the range of the measured concentrations reported in WWTP effluents and surface waters downstream from a WWTP (Ashton et al. 2004).

The anti-inflammatory drug ibuprofen can generate two main metabolites: carboxy and hydroxy-ibuprofen. Our calculated PECC values reported here are consistent with field measurements for the two metabolites, if we consider a WWTP removal fraction of 0.95 for the two compounds (Bendz et al. 2005). The PECC value of fenofibric acid calculated with aWWTPremoval fraction of 0.82 (Paffoni et al. 2006) is in the range of the surface water levels reported by Paffoni (Table 5). For other metabolites, no field data were available to allow any comparison; the following active metabolites-hydroxymetronidazole, norpropoxyphene, and demethyltramadol (excreted from metronidazole, dextropropoxyphene, and tramadol, respectively) - show PECB values for surface waters of approximately $250 \mathrm{ng} \cdot 1-1$. For oxazepam (benzodiazepine), a final PECB value was calculated by summing the PECs of different sources of oxazepam, which reached roughly $200 \mathrm{ng} \cdot \mathrm{l}-1$. Recent field measurements (Togola et al. 2007) reported an average concentration of oxazepam in surface water of about $200 \mathrm{ng} \cdot 1-1$, which is in good agreement with our calculated PEC.

\section{II.5. Calculation of Risk Quotients and Risk Assessment for Pharmaceuticals}

As a first attempt to prioritize pharmaceuticals, we calculated risk quotient ratios. According to the EMEA guideline (EMEA 2006), PNECs are calculated using assessment factors, as described in the European Technical Guidance Document (TGD 2003). Unlike TGD, the EMEA guideline enforces the use of chronic toxicity data and requires long-term NOEC for the base set (i.e ., three NOEC values from three different trophic levels, applying an assessment factor of 10 to the lowest value). The review of available ecotoxicity data showed that only six compounds bring together the conditions required by the EMEA guideline: clofibric acid, propranolol, carbamazepine, sulfamethoxazole, fluoxetine, and diclofenac. If we do not use only the EMEA guideline but also refer to the European TGD (2003) for pharmaceuticals with limited chronic data (1 or 2 NOECs from different trophic levels), it is then possible to calculate PNEC values and PEC/PNEC quotients for a further 16 compounds.

As all data required for calculating PECC values for pharmaceuticals were not always available, we used PECB values for furosemide, sertraline, paroxetine, citalopram, and fluoxetine and PECA values for carbamazepine, aspirin, and fluvoxamine. Results are displayed in Table 6. All risk quotients are less than one, except for amoxicillin, which presents a very high ratio of 62 , suggesting a risk for the aquatic environment. Nevertheless, a number of pharmaceuticals show a risk quotient close to 1 . This is the case for propranolol, ofloxacin, and erythromycin. For these molecules, a risk cannot be ruled out.

Three other molecules showed a risk ratio near 1, carbamazepine, sertraline, and furosemide. However, calculated PEC for carbamazepine is conservative and PNEC values for the two other compounds were calculated with an assessment factor of 100; therefore risk ratio is overestimated. Although reported to be one of the most toxic compounds, the serotoninergic antidepressant fluoxetine shows a low PEC/PNEC ratio, due to the very low PEC of $9 \mathrm{ng} \cdot 1-1$ calculated for this molecule. 


\section{DISCUSSION}

\section{III.1. Reliability of the PEC Calculation, Uncertainties, and Flaws}

Although field measurements are available for a limited number of pharmaceuticals, preliminary results indicate that PEC calculation is in accordance with environmental levels for pharmaceuticals. Therefore, the simple equation proposed here is valuable for predicting aquatic concentrations for pharmaceuticals in any country. Previously published works on exposure assessment of pharmaceuticals came to the same conclusion. Bound and Voulvoulis (2006) used EMEA guidelines to calculate PEC values and compared them with their own field measurements. They concluded that PEC calculation using the EMEA model could provide useful information for the prioritization of pharmaceuticals. The same conclusion was drawn by Liebig et al. (2006), who quoted that even if the EMEA model does not reflect the complexity of the real environment, it permits calculating PECs in accordance with field measurements. This study also reported that the factor with the highest impact and uncertainty was the production volume, estimated in the EMEA model in using Fpen and DOSEai. Using actual amounts of consumption, as in this study, and Fexcreta values give a reliable exposure assessment for pharmaceuticals.

Nevertheless, some uncertainties remain in the model we used. PEC values were calculated based on human consumption data during 1 year. As some pharmaceutical compounds are used both in human and veterinary medicine, there are still uncertainties about the actual amounts of pharmaceuticals reaching surface waters. This is particularly the case for antibiotic and antiprotozoal compounds. Theoretically, including veterinary consumption is likely to ensure a more comprehensive PEC. However, as the routes of administration and ways of reaching the aquatic environment differ between veterinary and human pharmaceuticals, this study only focused on human use.

Another major uncertainty remains on the quantity actually consumed by patients. Data provided by the AFSSAPS give information on the quantities delivered in hospitals and pharmacies per year but cannot give any information on the patient compliance. Patients' noncompliance can be quite large, and quantities actually consumed by people may be less than the quantities delivered, especially for drugs that do not require medical prescription as NSAIDs. Moreover, if data shared by the AFSSAPS provided a complete profile of the national annual consumption, no data were available regarding local consumptions of pharmaceuticals, which are likely to differ from one region to another. Finally, temporal variations of consumption (especially for pharmaceuticals used in acute treatments, such as antibiotics), and of quantities reaching the aquatic environment cannot be taken into account. Uncertainties also lie in the parameter Fstp: review of available data shows a high heterogeneity in removal rates. Moreover,WWTP efficiency toward pharmaceuticals can be influenced by the season (Castiglioni et al. 2006), therefore leading to varying surface water concentrations throughout the year.

At last, great uncertainties lie in the default values proposed by the model. For example, the default value for quantities of effluent is set to $2001 \cdot$ inhab-1.day-1, which is a mean value that can be accepted at the national scale in France. However, for some specific French regions, this value may drop to $1501 \cdot$ inhab-1.day-1. Using this last value in our calculation significantly 
increases PEC values by $25 \%$. To this extent, PEC values calculated for the WWTP effluents are more reliable than surface water PECs.

Equation (5) does not take into account the fraction of the molecule sorbed to sediment or suspended matter, which is a flaw in the proposed model. The EMEA model (Eq. [1]) includes this factor (FACTOR), but its calculation requires Koc values that are very scarce at the moment. In addition, Eq. (5) does not take into account abiotic and biotic degradation processes that can occur in surface waters. Abiotic processes are reported to be most important ones (Fent et al. 2006). Photolysis and hydrolysis were suggested to be rapid ways of removal of amoxicillin in the environment (Andreozzi et al. 2004). This statement was supported by the fact that amoxicillin was only detected in surface waters at low levels (Zuccato et al. 2005; Paffoni et al. 2006). The $\beta$-blocker propranolol was reported to be rapidly photodegraded and therefore is not expected to be persistent in surface waters (Qin-Tao and Williams 2007). Nevertheless, calculated PEC for propranolol was in the range of field measurements. This could be partially explained by the fact that propranolol and most of the pharmaceuticals are continuously released in the environment. This fact could balance the degradation processes in the environment, therefore some authors have suggested that pharmaceuticals should be considered as "pseudopersistent" contaminants due to this continuous release (Daughton and Ternes 1999).

\section{III.2. Relevance of Fexcreta Values}

As excretion rates range from 0.1 to 1 , they are to be taken into account in a prioritization or a risk assessment approach. Metabolism of pharmaceuticals is one of the first steps that limit the concentrations reaching the environment. Consequently, it is valuable to review such data and to search for the most accurate excretion values that would allow us to calculate more realistic PECs.

In this work, two main assumptions were made in the determination of the Fexcreta values. First, we did not take into account modifications of metabolism than can occur in unhealthy people (specifically people with hepatic or renal impairment). As an example: chronic renal failure can result in a decrease in propranolol metabolism via downregulation of hepatic cytochrome P450 activity (www.drugs.com, 2006), therefore potentially leading to increase excretion of unchanged drug. However, as people affected by renal or hepatic impairment may only represent a small part of the population, we considered that the resulting variability of the excretion fractions can be neglected when calculating PEC for the aquatic environment. Accuracy of PECs with field measurements presented here seems to confirm this assumption.

Second, we considered a worst case scenario for the Fexcreta values when more than one excretion fraction was given. This assumption, however, did not lead to high over-predictions of concentrations, as the variability of recovered values was limited and rarely exceeded 10\%; contrary to WWTP removal fractions. Only 4 compounds of the 76 showed a greater variability: sotalol (excretion rates values between 0.66 and 0.9$)$, clarithromycin $(0.18$ to 0.3$)$, ranitidine $(0.3$ to 0.5 ), and rifampicin for which excretion in urine is dose-dependant (Micromedex Drugdex_R 2006). 


\section{III.3. Environmental Relevance of Active Metabolites}

The metabolites reviewed should not be all of environmental concern. However, as no data exist about the ecotoxicity of these compounds, it is rather difficult to draw any conclusions. Moreover, it is not clear that pharmacologically inactive metabolites will not have any biological effects or toxicity on aquatic non-target organisms, especially lower invertebrates. Nevertheless, we will make a few suggestions to select the metabolites to search for in surface waters:

- The amount of the parent molecule consumed should be taken into account when selecting for relevant metabolites.

- Active metabolites that are pharmacologically equipotent to the parent compound should be considered unless they are excreted at low rates. Because it is not possible to propose a threshold excretion value using available data (metabolism, occurrence, and ecotoxicity), we assume a threshold value of $10 \%$, which is the value proposed by the EMEA (2006) to assess the relevance

- of a metabolic fraction of a pharmaceutical compound.

- Active metabolites showing a mechanism of action that is different from the parent compound should also be considered if their excretion fraction is equal to or greater than 0.1 .

- Because there are no data on the toxicity of pharmacologically inactive metabolites on aquatic organisms, such metabolites should be considered on a case-by case approach considering the amount of parent compound and their excretion fraction.

- Metabolites with an excretion fraction greater than the parent compound should be considered relevant for the aquatic environment.

- Active metabolites of prodrugs should be searched for in the environment.

Finally, it should be noted that no data are available on the potential toxicity of inactive metabolites, considering that the term "pharmacologically inactive metabolite" does not necessarily mean that such a metabolite has no effects on an aquatic organism. Considering these assumptions, we selected 30 environmentally relevant metabolites (Table 2) for which risk assessment should be implemented.

Only human metabolites were considered in this work. However, other degradation products can be generated in the environment, especially by photolysis. Photodegradation metabolites can be more toxic than the parent compound (Della- Greca et al. 2004; Isidori et al. 2005, 2006); and attention should also be paid on such metabolites.

\section{III.4. Considerations on Risk Assessment for Pharmaceuticals}

As quoted by several authors (Jones et al. 2002; Carlsson et al. 2006; Fent et al. 2006), ecotoxicological data, and notably chronic data, are lacking and thus limit the outcome of ERA based on risk quotients. Relevant chronic data are needed. Preliminary results presented here can nevertheless give some insight on the risk assessment of pharmaceuticals. Antibiotics and notably amoxicillin could present a risk for the aquatic environment. However, two points must be noted for this molecule. First, the NOEC value used to derive the PNEC is based on growth inhibition testing on the cyanobacteria Synechococcus leopoliensis (Andreozzi et al. 2003). If other 
available data on amoxicillin confirm that cyanobacteria seem very sensitive to amoxicillin

504 (Holten-Lutzoft et al. 1999), data on green algae species (Holten-Lutzoft et al. 1999) and on

Second, previous studies seem to indicate that amoxicillin is rapidly degraded in the aquatic environment (Andreozzi et al. 2004; Zuccato et al. 2005). Consequently, the risk ratio for amoxicillin could be smaller than predicted here. Nevertheless, antibiotics remain one of the more hazardous pharmaceutical classes for the aquatic environment due to their antimicrobial activity. Among antibiotics, macrolides, which are not only toxic toward cyanobacteria but also toward green algae (Isidori et al. 2005), may represent a class of compounds of high concern for the aquatic environment.

Although reported to be one of the most toxic compounds, the serotoninergic antidepressant fluoxetine shows a low PEC/PNEC ratio (0.09), due to the very low PEC of 9 ng.1-1 calculated for this molecule. It should be noted that the active metabolite norfluoxetine, with similar pharmacological activity, may act additively with fluoxetine. It therefore seems reasonable to consider the sum of the two PEC values (fluoxetine + norfluoxetine) in the calculation of the risk quotient, which increases the fluoxetine risk quotient to 0.26 , still less than 1 but 3 times greater than the previous value. Metabolites should be considered when performing a pharmaceutical ERA, at least for PEC calculation. However, it is not yet possible to assess the hazard of these metabolites, due to the lack of ecotoxicity data. For metabolites that are reported to be equipotent (the same mechanism of action and pharmacological potency) to the parent compound, using the sum of respective PECs may be appropriate. For active metabolites with differences in pharmacological potency but with the same mechanism of action, it will be necessary to take their relative potency into account. For metabolites with a mechanism of action different from the parent compound, however, ecotoxicological data remain necessary to assess their toxicity.For non-pharmacologically active metabolites that may have toxic effects on aquatic organisms, it is also necessary to build ecotoxicological assays.

Finally, in the context of an ERA, an effort should be made on the study of the effect of pharmaceuticals mixtures on aquatic organisms for several reasons. First, pharmaceuticals with the same mechanism of action may act additively on aquatic organisms (Cleuvers 2003; Fraysse and Garric 2005). Therefore, in a risk assessment framework, such pharmaceuticals should be considered together. As an example, for SSRIs, summed PECs of all parent compounds (and also active metabolites) should be taken into account rather than considering separate PECs; moreover the ecotoxicological effects of such mixtures should be better evaluated.

Second, interactions between pharmaceuticals are well studied and taken into account in humans as the concomitant use of some pharmaceuticals can lead to severe consequences. Mixtures of pharmaceuticals known to interact with each other should be assessed for ecotoxicity. Third, a number of pharmaceuticals are cytochrome P450 enzyme modulators or Para-glycoprotein-P modulators (proteins that play a key role in the resistance to xenobiotics), and thus are likely to disrupt homeostasis of non-target organism and to increase their sensitivity to other pollutants (Endicoot and Ling 1989; Toomey and Epel 1993). Therefore, one of the major issues when considering concentrations entering the environment should be interactions between pharmaceuticals or between pharmaceuticals and other pollutants: single-compound assays are not sufficient to provide accurate environmental risk assessment of pharmaceuticals. 
Nevertheless, except for a few laboratory (Cleuvers 2003; Eguchi et al. 2004; Fraysse and Garric 2005; Chritensen et al. 2007), and microcosms studies (Brain et al. 2004; Richards et al. 2004) the ecotoxicological assays done to date only focus on single compounds.

\section{III.5. Considerations on the Prioritization of Pharmaceuticals}

Equation (5) can be used to assess the environmental exposure for pharmaceuticals. If all data were available, a preliminary prioritization based on PEC values could be conducted. However,WWTPremoval rates are scarce and limit such an approach. In addition, the effects are not taken into account, and such a simple approach does not allow to select the compounds showing the highest risk. To fill this lack and to provide an initial hazard assessment of pharmaceuticals, some authors have proposed the use of QSAR and a test battery based on mechanism of action (Escher et al. 2006; Lienert et al. 2007).

We consider, as do several authors, that the use of existing pharmacological, toxicological, and pharmacokinetic data is likely to be helpful in assessing the risk of pharmaceuticals, as they could provide a better understanding of the fate and effect of pharmaceuticals in the aquatic environment (Lange and Dietrich 2002; Seiler 2002; Fent et al. 2006; Jjemba 2006). The use of mammalian pharmacological and toxicological data was proposed to help to prioritize the potential impacts of pharmaceuticals to fish (Huggett et al. 2003). In practice, pharmacokinetic parameters such as bioavailability, half-life in the human body or excretion rates may be used as indicators of the environmental behaviour of pharmaceuticals in the aquatic environment. Jjemba (2006) suggested that compounds excreted unchanged in low amounts may also show low degradability in the environment. As the pharmacokinetic behavior is influenced by the same parameters that can modify environmental behavior such as $\mathrm{pH}$ and $\mathrm{pKa}$, it makes sense to draw a parallel between pharmacokinetic and environmental criteria. Williams et al. (2006) very recently studied the correlation between the environmental partitioning coefficient $\mathrm{Kd}$ and the distribution volume $\mathrm{Vd}$, which measures the distribution of a pharmaceutical within the body. These results suggest that pharmacokinetic parameters should be helpful to estimate environmental behavior for pharmaceuticals. Known side effects of pharmaceuticals may also be valuable to indicate potential harmful effects on nontarget organisms as it as already been shown for diclofenac in vultures (Oaks et al. 2004), and in fish (Schwaiger et al. 2004; Triebskorn et al. 2004). Taking into account such effects could make it possible to target the harmful impacts of these compounds, at least on non-target vertebrates.

Comparative pharmacology could also be useful to understand toxicity pathways of pharmaceuticals. At the moment, studies have only considered the major mechanism of action (MoA) of pharmaceuticals in ecotoxicity assays. However, evidence shows that compounds belonging to same pharmacological and chemical classes (e.g., compounds with same mechanisms of action), can display a high variability in toxic values on same species and endpoints (Huggett et al. 2002; Henry et al. 2004; Dzialowski et al. 2006; Garric et al. 2006). Indeed, pharmaceuticals are not only characterized by their principal MoA but also by some additional pharmacological characteristics that should be taken into account. In the case of $\beta$ blockers, several authors (e .g., Fraysse and Garric 2005; Fent et al. 2006) have suggested that differences in toxicity should be partially explained by pharmacological properties specific to these compounds such as receptor selectivity or membrane-stabilizing activity. For SSRIs, results from Henry et al. (2004) show that NOEC values on the reproduction of $C$. dubia range more 
than two orders of magnitude. Pharmacological data indicate that even if SSRIs have a greater selectivity for blocking serotonin reuptake (their principal MoA), they also have affinities to some other receptors and reuptake inhibitor activities on other systems such as the noradrenergic or dopaminergic systems (Hyttel 1993; Dulin et al. 2002). Such "secondary" MoAs could help to understand toxic responses. Sertraline is both the most toxic SSRI on C. dubia reproduction (Henry et al. 2004) and the most potent inhibitor of serotonin reuptake (Hyttel 1993); however, it is not the most selective SSRI, as it also exerts an activity on dopamine and noradrenaline reuptake (Hyttel 1993). Citalopram, which is the less toxic SSRI (Henry et al. 2004), is not the less potent molecule but the most selective one. Such pharmacological data suggest that the toxic response observed for $C$. dubia could not only be linked to serotonin reuptake but also to other MoAs; this hypothesis remains to be confirmed.

A prioritization methodology for pharmaceuticals could therefore cross PEC values with relevant pharmacological data, such as specific mechanism of action or relevant chronic adverse effects, to give a reliable estimation of the risk. Such a methodology should allow to bypass the lack of ecotoxicological data and could provide useful information for building ecotoxicological assays.

\section{CONCLUSION}

The main objective of this study was to assess the exposure concentration of pharmaceuticals in surface water with an emphasis on metabolites. The PEC calculation proposed here is reliable, as calculated PECs are in good agreement with field measurements. Metabolism data are important to take into account as they allow a more relevant selection of pharmaceuticals and metabolites to survey in aquatic ecosystems. Moreover, there is a need to consider the specificity of drugs consumption profile for each country, as such a specificity can lead to different priority compounds. Another objective was to perform a preliminary prioritization using risk quotients ratios. Given the lack of relevant ecotoxicological data, it was not possible to prioritize pharmaceuticals using risk ratios. As it will take time to build enough ecotoxicological data, we consider that the use of pharmacokinetic and pharmacological data can help to prioritize pharmaceuticals. Moreover, comparative pharmacology based on mechanism of action, adverse effects, and specific activities could be usefully taken into account to better understand the mechanisms of toxicity of pharmaceuticals and to assess their environmental risk. The next step in our work is to propose a sound selection of pharmaceuticals to be monitored in surface waters by implementing a prioritization methodology based on an exposure assessment crossed with a biological affect assessment using ecotoxicological and pharmacological data.

\section{ACKNOWLEDGMENTS}

The authors thank the AFSSAPS (Cavali'e Philippe, Rouleau Alice, and Castot Anne), for kindly sharing consumption data of pharmaceuticals. The authors also thank Tatiana Boucard (UK Environment Agency) for kindly proofreading the former manuscript. The authors also thank the Agence de l'Eau Rhône Méditerranée \& Corse for financially supporting this project. Finally, the authors are grateful to the two anonymous reviewers for their helpful comments that allowed us to improve this article. 


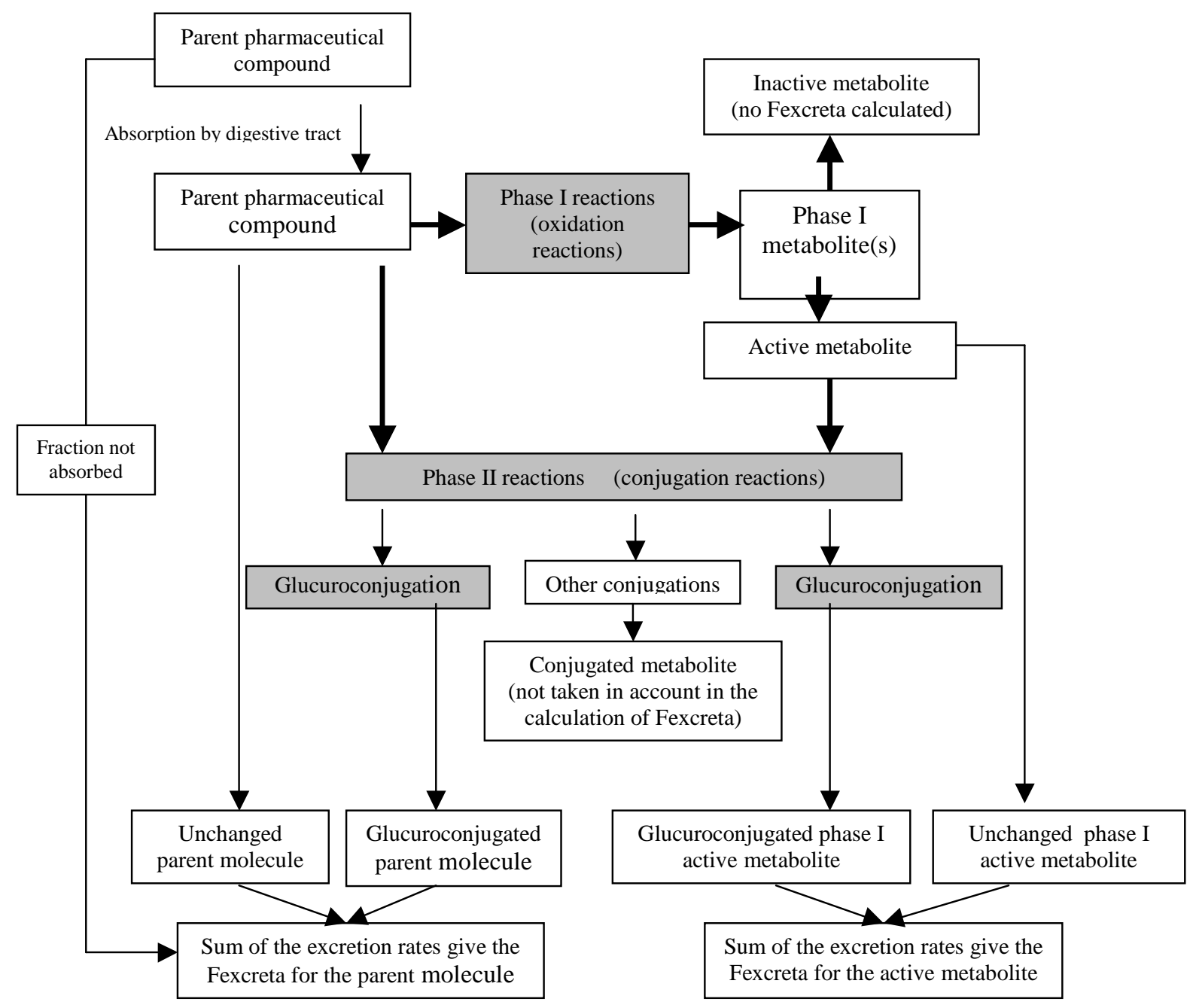

Figure 1. Methodology used to calculate Fexcreta values for pharmaceutical compounds and active metabolites. As glucuroconjugated metabolites can be cleaved in the environment and regenerate the active compound, their excretion rates were taken into account in the calculation of the Fexcreta value. 


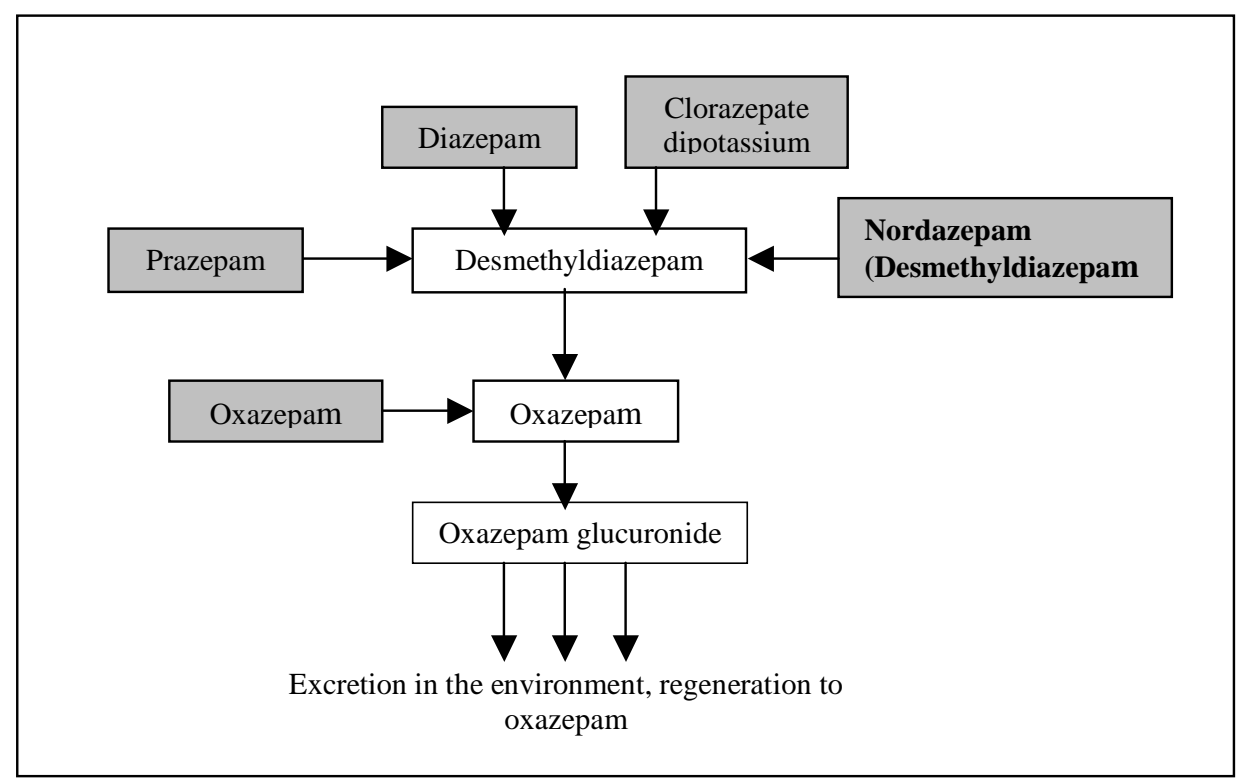

Figure 2. Simplified scheme of the different sources of oxazepam. Grey squares indicate an active molecule used as a commercialized product; white squares indicate metabolites. 
Table 1. Consumption, excretion fractions (Fexcreta) and calculated PECs for pharmaceuticals used in France in 2004 (Data from

AFSSAPS 2006). Active molecules are sorted by decreasing consumption amounts. PEC are calculated using equation 5 and are expressed in $n g .1^{-1}$. $\mathrm{PEC}_{\mathrm{A}}$ are calculated using actual amounts only. $\mathrm{PEC}_{\mathrm{B}}$ are $\mathrm{PEC}_{\mathrm{A}}$ refined by Fexcreta values.

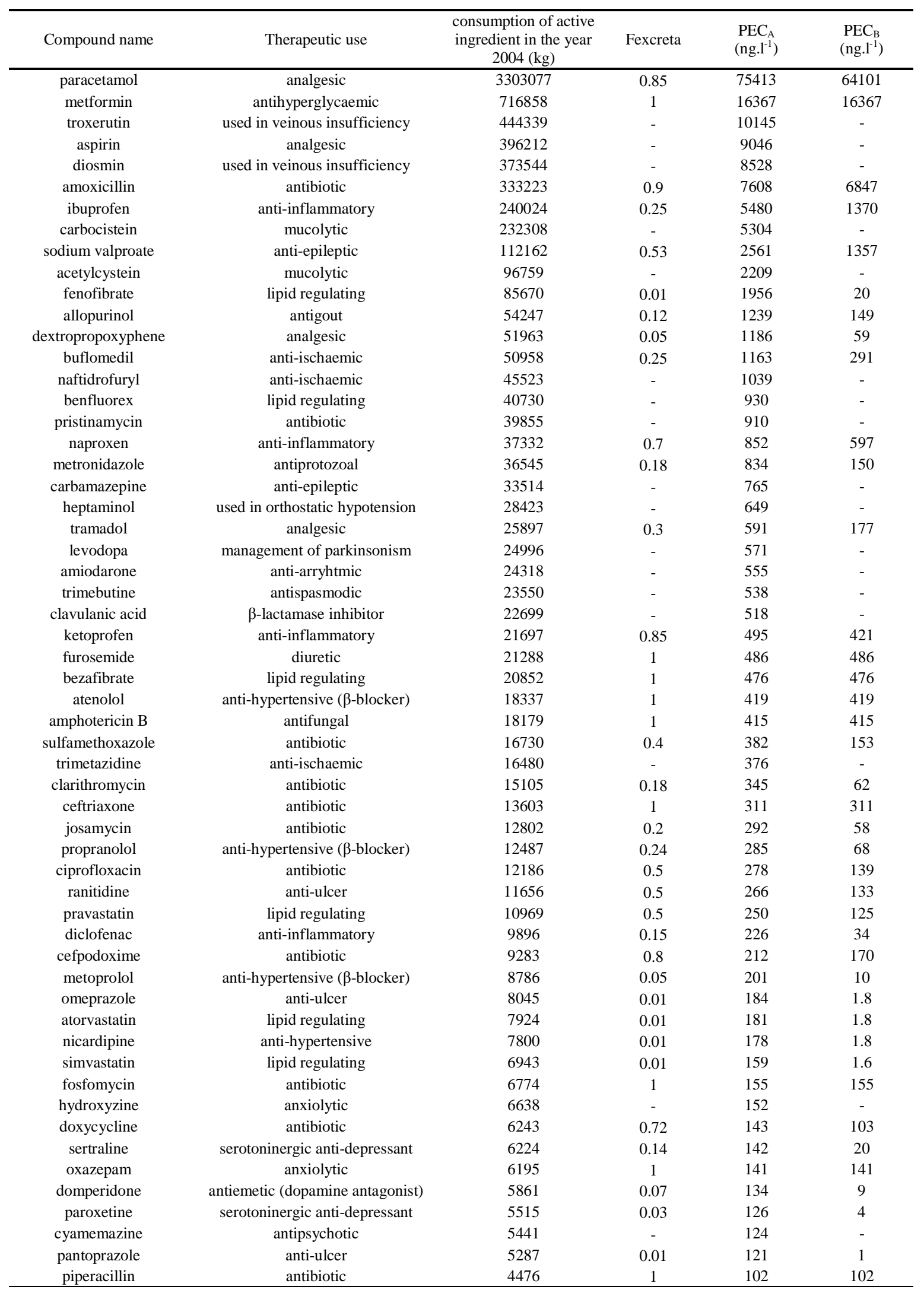


Table 1. continued

\begin{tabular}{|c|c|c|c|c|c|}
\hline Compound name & Therapeutic class & $\begin{array}{c}\text { consumption of active } \\
\text { ingredient in the year } \\
2004(\mathrm{~kg})\end{array}$ & Fexcreta & $\begin{array}{c}\mathrm{PEC}_{\mathrm{A}} \\
(\text { ng.l-1) }\end{array}$ & $\begin{array}{c}\mathrm{PEC}_{\mathrm{B}} \\
\text { (ng.l-1) } \\
\end{array}$ \\
\hline ofloxacin & antibiotic & 4137 & 1 & 94 & 94 \\
\hline azithromycin & antibiotic & 4073 & 0.5 & 93 & 46.5 \\
\hline phenobarbital & anti-epileptic & 3915 & 0.25 & 89 & 22.3 \\
\hline prednisolone & corticoid & 3743 & - & 85 & - \\
\hline fluoxetine & serotoninergic anti-depressant & 3740 & 0.1 & 85 & 8.5 \\
\hline citalopram & serotoninergic anti-depressant & 3487 & 0.4 & 80 & 32 \\
\hline roxythromycin & antibiotic & 3404 & 0.5 & 78 & 38.9 \\
\hline trimethoprim & antibiotic & 3346 & 0.5 & 76 & 38.2 \\
\hline zolpidem & hypnotic & 3344 & 0.01 & 76 & 0.76 \\
\hline bromazepam & anxiolytic & 2604 & 0.03 & 59 & 1.78 \\
\hline mianserine & antipsychotic & 2423 & - & 55.3 & - \\
\hline rifampicine & antibiotic & 2383 & 0.18 & 54 & 9.8 \\
\hline prazepam & anxiolytic & 2166 & 0.03 & 49 & 1.48 \\
\hline tianeptine & antidepressant & 2152 & 0,08 & 49 & 3.93 \\
\hline bisoprolol & anti-hypertensive ( $\beta$-blocker) & 2113 & 0.6 & 48 & 28.94 \\
\hline clorazepate & anxiolytic & 2109 & 0.01 & 48 & 0.48 \\
\hline amlodipine & anti-hypertensive & 2013 & 0.1 & 46 & 4.60 \\
\hline piroxicam & anti-inflammatory & 2008 & 0.1 & 46 & 4.58 \\
\hline zopiclone & hypnotic & 1948 & 0.04 & 44 & 1.78 \\
\hline ceftazidime & antibiotic & 1832 & 1 & 42 & 41,82 \\
\hline levomepromazine & antipsychotic & 1699 & - & 39 & - \\
\hline prednisone & corticoid & 1550 & - & 35 & - \\
\hline cetirizine & anti-allergic & 1442 & 0.7 & 33 & 23.05 \\
\hline fluvoxamine & serotoninergic anti-depressant & 1121 & - & 26 & - \\
\hline glibenclamide & antihyperglycaemic & 1092 & 0.1 & 25 & 2.49 \\
\hline baclofen & muscle relaxant & 1080 & 0.8 & 25 & 19.72 \\
\hline ramipril & antihypertensive & 1042 & 0.02 & 24 & 0.48 \\
\hline loxapine & antipsychotic & 961 & - & 22 & - \\
\hline nadolol & anti-hypertensive ( $\beta$-blocker) & 938 & 1 & 21 & 21.42 \\
\hline loratadine & anti allergic & 927 & - & 21 & - \\
\hline vancomycin & antibiotic & 918 & 1 & 21 & 20.96 \\
\hline metoclopramide & antiemetic (dopamine antagonist) & 913 & 0.3 & 21 & 6.25 \\
\hline fluconazole & antifungal & 893 & 0.8 & 20 & 16.30 \\
\hline lorazepam & anxiolytic & 585 & 0.85 & 13 & 11.35 \\
\hline tazobactam & $\beta$-lactamase inhibitor & 560 & 0.8 & 13 & 10.22 \\
\hline diazepam & anxiolytic & 526 & 0.01 & 12 & 0.12 \\
\hline perindopril & anti-hypertensive & 504 & 0.1 & 12 & 1.15 \\
\hline hydrocortisone & corticoid & 453 & - & 10 & - \\
\hline oxprenolol & anti-hypertensive ( $\beta$-blocker) & 377 & 0.98 & 8.60 & 8.43 \\
\hline tropatepine & management of parkinsonism & 355 & - & 8.11 & - \\
\hline haloperidol & antipsychotic & 342 & - & 7.81 & - \\
\hline loperamide & antidiarrhoeal & 318 & - & 7.26 & - \\
\hline carvedilol & anti-hypertensive ( $\beta$-blocker) & 313 & - & 7.15 & - \\
\hline buprenorphine & opioid & 270 & - & 6.17 & - \\
\hline trihexyphenidyle & management of parkinsonism & 257 & - & 5.86 & - \\
\hline nordazepam & anxiolytic & 237 & 0.01 & 5.4 & 0.05 \\
\hline alprazolam & anxiolytic & 178 & 0.01 & 4.05 & 0.04 \\
\hline terbutaline & anti-asthmatic & 165 & - & 3.78 & - \\
\hline betamethasone & corticoid & 156 & - & 3.56 & - \\
\hline teicoplanin & antibiotic & 136 & 1 & 3.11 & 3.11 \\
\hline midazolam & hypnotic / amnestic & 98 & - & 2.23 & - \\
\hline levothyroxin & thyroid hormone & 59 & - & 1.34 & - \\
\hline ondansetron & anti-emetic & 44 & 0.1 & 1.00 & 0.10 \\
\hline clonazepam & anxiolytic & 21 & - & 0.49 & - \\
\hline escitalopram & serotoninergic anti-depressant & 4.6 & - & 0.11 & - \\
\hline
\end{tabular}


Table 2. Review of phase I metabolites of potential interest for the French aquatic environment. Active metabolites are sorted in alphabetical order of parent compounds, except for oxazepam. Underlined metabolites are considered to be of environmental concern (see section about environmental relevance of active metabolites for further details).

\begin{tabular}{|c|c|c|c|}
\hline Active metabolite & Fexcreta & Parent compound & Pharmacological activity \\
\hline$\underline{\text { diacetolol }}$ & 0.5 & acebutolol & equipotent to parent compound \\
\hline oxypurinol & ND & allopurinol & less active than parent compound \\
\hline N-desethylamiodarone & ND & amiodarone & $\begin{array}{l}\text { equipotent as sodium channel blocker } \\
\text { less active as antagonist of the calcium channel }\end{array}$ \\
\hline nortryptiline & ND & amitriptyline & active, no further details \\
\hline$\underline{\text { salicylic acid }}$ & ND & aspirin * & active, related to the pharmacological effect \\
\hline 2-hydroxy-atorvastatin & ND & atorvastatin * & active, related to the pharmacological effect \\
\hline 4-hydroxy-atorvastatin & ND & atorvastatin * & active, related to the pharmacological effect \\
\hline$\beta$-acid metabolite & 0.05 & baclofen & active, no further details \\
\hline 10,11-epoxy metabolite & ND & carbamazepine & active, partially responsible for carbamazepine intoxication \\
\hline desmethylcarvedilol & ND & carvedilol & 2.5 times more potent in rabbits \\
\hline 4-OH-phenylcarvedilol & ND & carvedilol & 13 times more potent in rabbits \\
\hline 4 different metabolites & $\begin{array}{c}0.22 \text { (all } \\
\text { metabolites) }\end{array}$ & ciprofloxacin & some metabolites may have an antibacterial activity \\
\hline$\underline{14-\mathrm{OH} \text {-clarithromycin }}$ & 0.15 & clarithromycin & $\begin{array}{c}\text { more active on certain bacterial strains }(H \text { influenza }) \text {, } \\
\text { synergistic action with clarithromycin }\end{array}$ \\
\hline clofibric acid & 0.99 & clofibrate $*$ & active, linked to the pharmacological effect \\
\hline norpropoxyphene & 0.25 & dextropropoxyphene & $\begin{array}{l}\text { substantially less central-nervous-system depressant effect } \\
\text { than dextro but a greater local anaesthetic effect }\end{array}$ \\
\hline$\underline{\text { fenofibric acid }}$ & 0.6 & fenofibrate * & active, linked to the pharmacological effect \\
\hline$\underline{\text { norfluoxetine }}$ & 0.2 & fluoxetine & equipotent to parent compound \\
\hline cetirizine & ND & hydroxyzine & active, used as patent medicine \\
\hline 2-OH-ibuprofen & 0.25 & ilbuprofen & no data on pharmacological activity \\
\hline$\underline{\text { carboxy-ibuprofen }}$ & 0.37 & ilbuprofen & no data on pharmacological activity \\
\hline desipramine & 0.06 & imipramine & equipotent to parent compound \\
\hline OH-metronidazole & 0.28 & metronidazole & between 30 and $50 \%$ of the metronidazole activity \\
\hline desmethylnaproxen & 0.28 & naproxen & may be pharmacologically inactive \\
\hline unidentified metabolites & 0.08 & norfloxacin & some metabolites may have an antibacterial activity \\
\hline perindoprilat & 0.38 & perindopril * & active, linked to the pharmacological effect \\
\hline 4-OH-propranolol & ND & propranolol & equipotent to parent compound \\
\hline$\underline{\text { ramiprilat }}$ & 0.12 & ramipril * & 6 times more active than ramipril \\
\hline 25-O-deacetylrifampicin & about 0.5 & rifampicin & equipotent to parent compound \\
\hline B-OH-acid metabolite & $0.55 * *$ & $\operatorname{simvastatin} *$ & active, linked to the pharmacological effect \\
\hline acetylsulfamethoxazole & 0.6 & sulfamethoxazole & no antibacterial activity \\
\hline$\underline{\text { demethyltramadol }}$ & 0.6 & tramadol & active, analgesic effect, no further details \\
\hline O-desmethylvenlafaxine & 0.3 & venlafaxine & active, no further details \\
\hline Zopiclone-N-oxide & 0.15 & zopiclone & less active than parent compound \\
\hline \multirow{4}{*}{ oxazepam } & 1 & diazepam & \multirow{4}{*}{$\begin{array}{l}\text { active, used as a patent anxiolytic } \\
\text { (see section 3.2) }\end{array}$} \\
\hline & 1 & clorazepate & \\
\hline & 1 & nordazepam & \\
\hline & ND & & \\
\hline
\end{tabular}

ND : no excretion rate value could be determined.

* Indicates a prodrug.

** Data from Carlsson et al., 2006. 
Table 3. Wastewater treatment plants (WWTPs) removal fraction for pharmaceuticals and metabolites

\begin{tabular}{|c|c|c|c|c|c|c|c|c|c|c|}
\hline & \multicolumn{8}{|c|}{ Wastewater treatment plants removal fraction } & \multirow[b]{2}{*}{ min value } & \multirow[b]{2}{*}{$\max$ value } \\
\hline & Ternes 1998 & $\begin{array}{c}\text { Stumpf } e t a l . \\
1999\end{array}$ & Paxéus 2004 & $\begin{array}{l}\text { Bendz et al. } \\
2005\end{array}$ & $\begin{array}{c}\text { Clara et al. } \\
2005\end{array}$ & $\begin{array}{l}\text { Paffoni et al. } \\
2006 \\
\end{array}$ & $\begin{array}{c}\text { Castiglioni et al., } \\
2006^{*} \\
\end{array}$ & $\begin{array}{c}\text { Castiglioni et al., } \\
2006 * * \\
\end{array}$ & & \\
\hline amoxicillin & & & & & & 0.29 & $0.49-1(\mathrm{md}=0.75)$ & 1 & 0.29 & 1 \\
\hline atenolol & & & $<0.1$ & & & 0.52 & $0-0.21(\mathrm{md}=0.1)$ & $0.36-0.76(\mathrm{md}=0.55)$ & 0 & 0.76 \\
\hline azithromycin & & & & & & 0.43 & & & & 0.43 \\
\hline bezafibrate & 0.83 & 0.5 & & & $0.4->0.9$ & 0.72 & $0-0.66(\mathrm{md}=0.15)$ & $0-0.98(\mathrm{md}=0.87)$ & 0 & 0.98 \\
\hline carbamazepine & 0.07 & & $<0.1-0.53$ & 0.3 & & 0.19 & 0 & 0 & 0 & 0.19 \\
\hline ciprofloxacin & & & & & & 0.62 & $0.45-0.78(\mathrm{md}=0.6)$ & $0.53-0.69(\mathrm{md}=0.63)$ & 0.45 & 0.78 \\
\hline clarithromycin & & & & & & 0.69 & $0-0.24(\mathrm{md}=0)$ & 0 & 0 & 0.69 \\
\hline diclofenac & 0.69 & 0.75 & $<0.1-0.8$ & 0.22 & & 0.27 & & & 0.1 & 0.75 \\
\hline doxycycline & & & & & & 0.06 & & & & 0.06 \\
\hline fenofibrate & & & & & & $>0.01$ & & & & $>0.1$ \\
\hline fenofibric acid & 0.64 & 0.45 & & & & 0.82 & & & 0.45 & 0.82 \\
\hline furosemide & & & & & & & $0-0.17(\mathrm{md}=0.8)$ & $0.15-0.62(\mathrm{md}=0.54)$ & 0 & 0.62 \\
\hline ibuprofen & 0.09 & 0.75 & $0.52-0.99$ & 0.96 & $>0.9$ & 0.96 & $0.25-0.72(\mathrm{md}=0.38)$ & $0-1(\mathrm{md}=0.93)$ & 0 & 1 \\
\hline OH-ibuprofen & & & & 0.95 & & & & & & 0.95 \\
\hline carboxy-ibuprofen & & & & 0.96 & & & & & & 0.96 \\
\hline ketoprofen & & 0.69 & & 0.65 & & 0.93 & & & 0.65 & 0.93 \\
\hline metoprolol & 0.83 & & $<0.1-0.1$ & & & 0.1 & & & 0.1 & 0.83 \\
\hline naproxen & 0.66 & 0.78 & $0.48-0.93$ & 0.93 & & 0.88 & & & 0.48 & 0.93 \\
\hline ofloxacin & & & & & & 0.4 & $0-0.62(\mathrm{md}=0.43)$ & $0.33-0.66(\mathrm{md}=0.57)$ & 0 & 0.66 \\
\hline propranolol & 0.96 & & & 0.32 & & 0.22 & & & 0.22 & 0.96 \\
\hline ranitidine & & & & & & & $0-0.76(\mathrm{md}=0.39)$ & $0.72-0.89(\mathrm{md}=0.84)$ & 0 & 0.84 \\
\hline roxithromycin & & & & & $0.5-0.6$ & 0.51 & & & 0.5 & 0.6 \\
\hline spiramycine & & & & & & 0.94 & $0-0.11(\mathrm{md}=0)$ & 0 & 0 & 0.94 \\
\hline sulfamethoxazole & & & & & $0.5-0.6$ & 0.64 & & & 0.5 & 0.64 \\
\hline trimethoprim & & & $<0.1-0.4$ & 0.49 & & 0.51 & & & 0.1 & 0.51 \\
\hline vancomycin & & & & & & 1 & & & & 1 \\
\hline
\end{tabular}

md : median value

*: removal fraction determined in winter (Castiglioni et al. 2006).

**: removal fraction determined in summer (Castiglioni et al. 2006). 
Table 4. Comparison of calculated PEC for wastewater treatment plants (WWTP) effluents with field measurements conducted in France.

PEC are determined using equation (5) and are expressed in $n g .1^{-1}$.

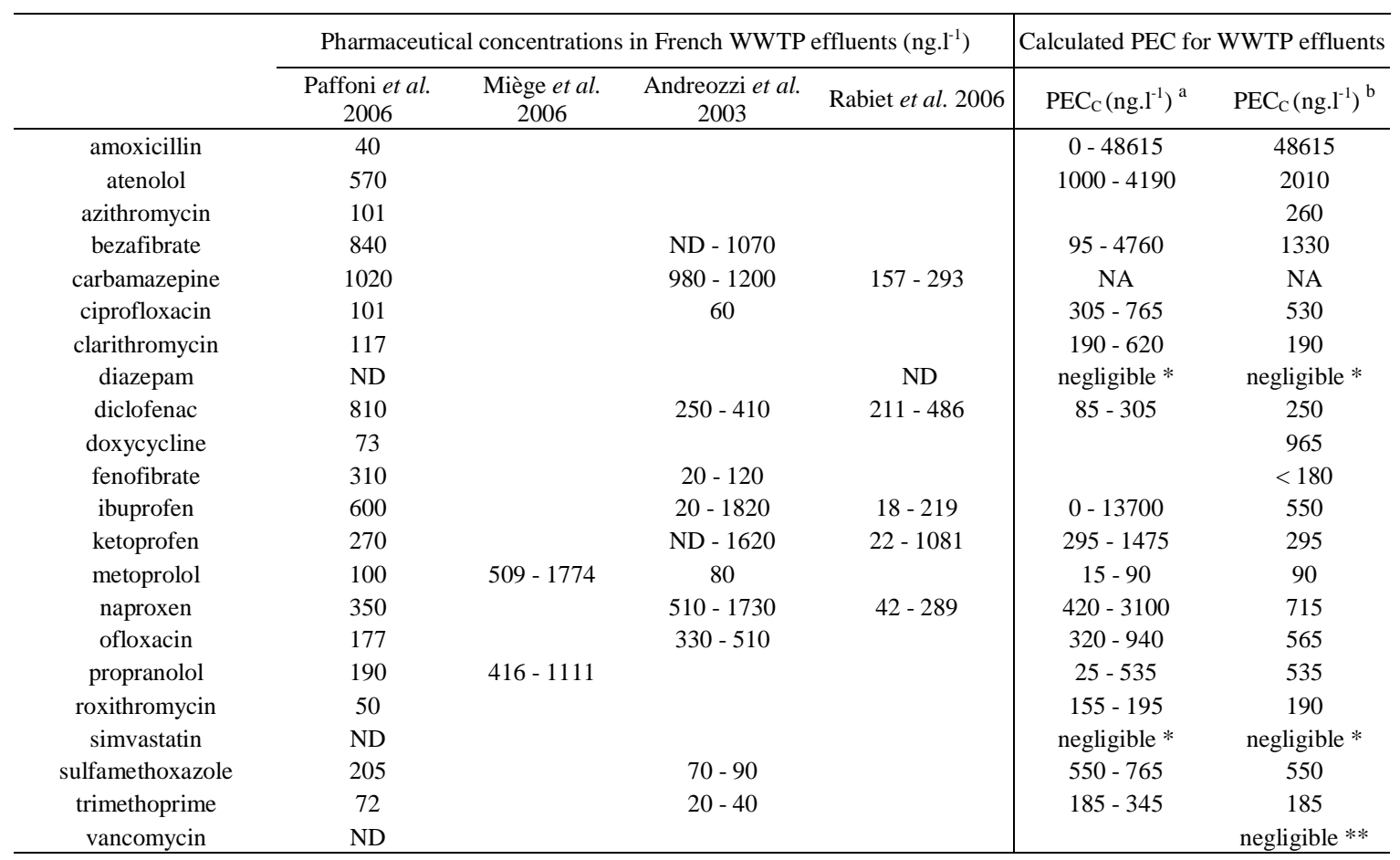

ND: not detected in WWTP effluents

NA: not applicable: carbamazepine Fexcreta values were not determined in this study.

a: distribution of PEC calculated using minimal and maximal WWTP removal rates reviewed (see table 3 for details)

b: PEC calculated using WWTP removal rates calculated by Paffoni et al., 2006.

*: PECc are considered negligible considering the very low Fexcreta values of 0.01 assumed for diazepam and simvastatin.

**: PECc is considered negligible as Paffoni et al. (2006) reports a WWTP removal fraction of 1.

WWTP measured concentrations from Paffoni et al. (2006) are mean concentrations. 
Table 5. Calculated surface water PEC values for relevant metabolites.

\begin{tabular}{|c|c|c|c|c|c|}
\hline Metabolite & $\operatorname{PEC}_{B}\left(\right.$ ng..$\left.^{-1}\right)$ & $\mathrm{PEC}_{\mathrm{C}}\left(\mathrm{ng} \cdot \mathrm{l}^{-1}\right)$ & $\begin{array}{c}\text { measured } \\
\text { concentration }\end{array}$ & sample & reference \\
\hline salicylic acid & NA & NA & 25 & surface water & Ternes, 1998 \\
\hline acetylsulfamethoxazole & 230 & NA & $\begin{array}{l}161^{\mathrm{a}} \\
70^{\mathrm{a}}\end{array}$ & $\begin{array}{c}\text { WWTP effluent } \\
\text { downstream WWTP }\end{array}$ & Ashton et al. 2004 \\
\hline hydroxy-ibuprofen & 1370 & 70 & $\begin{array}{l}50 \\
20\end{array}$ & $\begin{array}{c}\text { WWTP effluent } \\
\text { downstream WWTP }\end{array}$ & \multirow{2}{*}{ Bendz et al. 2005} \\
\hline carboxy-ibuprofen & 2025 & 100 & $\begin{array}{l}430 \\
230\end{array}$ & $\begin{array}{c}\text { WWTP effluent } \\
\text { downstream WWTP }\end{array}$ & \\
\hline 14-OH-clarithromycin & 50 & NA & ND & - & - \\
\hline OH-metronidazole & 235 & NA & ND & - & - \\
\hline 25-O-deacetyl-rifampicin & 25 & NA & ND & - & - \\
\hline norfluoxetine & 17 & NA & ND & - & - \\
\hline oxazepam & $205^{\mathrm{c}}$ & NA & 1500 & surface water & Togola et al., 2007 \\
\hline zopiclone $\mathrm{N}$-oxide & 7 & NA & ND & - & - \\
\hline norpropoxyphene & 295 & NA & ND & - & - \\
\hline demethyltramadol & 355 & NA & ND & - & - \\
\hline$\beta$-OH-acid metabolite $*$ & 90 & NA & ND & - & - \\
\hline fenofibric acid & 1175 & 2068 & $\begin{array}{l}1260^{\mathrm{a}} \\
380^{\mathrm{b}} \\
45^{\mathrm{b}}\end{array}$ & $\begin{array}{l}\text { WWTP effluent } \\
\text { WWTP effluent } \\
\text { surface water }\end{array}$ & Paffoni et al. 2006 \\
\hline perindoprilat & 4 & NA & ND & - & - \\
\hline ramiprilat & 3 & NA & ND & - & - \\
\hline
\end{tabular}

PEC values were calculated using equation 5. Sample and references report to measured concentrations.

All PECs are calculated for surface waters except the PEC for fenofibric acid which is calculated for WWTP effluents.

*: active metabolite of simvastatin.

a: mean values.

b: median values.

c: oxazepam PEC was calculated by summing different sources for this compound.

ND: not detected or not already searched in the aquatic environment.

NA: not applicable due to lack of data. 
Table 6. Determination of risk quotients for pharmaceutical compounds (compounds are sorted by decreasing risk ratios values).

\begin{tabular}{|c|c|c|c|c|c|c|c|c|c|c|}
\hline compound & most sensible specie & taxa & endpoint & $\begin{array}{l}\text { reference of the } \\
\text { ecotoxicological assay }\end{array}$ & AF used & $\begin{array}{l}\text { PNEC final } \\
\text { value } \\
\left(\text { ng. } .^{-1}\right)\end{array}$ & $\begin{array}{l}\mathrm{PEC}_{\mathrm{A}} \text { value } \\
\left(\text { ng. } .^{-1}\right)\end{array}$ & $\begin{array}{c}\mathrm{PEC}_{\mathrm{B}} \text { value } \\
\left(\text { ng. }^{-1} \mathrm{I}^{-1}\right)\end{array}$ & $\begin{array}{l}\mathrm{PEC}_{\mathrm{C}} \text { value } \\
\left.\left(\text { ng. }^{-1}\right)^{-1}\right)\end{array}$ & $\begin{array}{c}\mathrm{PEC} / \mathrm{PNEC} \\
\text { ratio }\end{array}$ \\
\hline amoxicillin & S. leopoliensis & cyanobacteria & growth & Andreozzi et al. 2004 & $10 *$ & 78 & & & 4860 & 62.3 \\
\hline aspirin & Daphnia. magna & cladoceran & reproduction & Marques et al. 2004 & 100 & 10000 & 9046 & & & 0.9 \\
\hline ofloxacin & S. leopoliensis & cyanobacteria & growth & Ferrari et al. 2004 & 50 & 100 & & & 56.5 & 0.56 \\
\hline propranolol & Hyallela azteca & gammaridae & reproduction & Huggett et al. 2002 & $10 *$ & 100 & & & 54.5 & 0.54 \\
\hline carbamazepine & Ceriodaphnia dubia & cladoceran & reproduction & Ferrari et al. 2004 & $10 *$ & 2500 & 765 & & & 0.31 \\
\hline furosemide & Ceriodaphnia. dubia & cladoceran & reproduction & Isidori et al. 2006 & 100 & 1560 & & 486 & & 0.31 \\
\hline clarithromycin & D. magna & cladoceran & reproduction & Yamashita et al. 2006 & 50 & 62 & & & 19 & 0.3 \\
\hline diclofenac & Ceriodaphnia dubia & cladoceran & reproduction & Ferrari et al. 2004 & $10 *$ & 100 & & & 25 & 0.25 \\
\hline sertraline & Ceriodaphnia. dubia & cladoceran & reproduction & Henry et al. 2003 & 100 & 90 & & 20 & & 0.22 \\
\hline sulfamethoxazole & S. leopoliensis & cyanobacteria & growth & Ferrari et al. 2004 & $10 *$ & 590 & & & 55 & 0.1 \\
\hline fluoxetine & unspecified & chlorophyceae & growth & FDA-CDER 1996 & $10 *$ & 100 & & 9 & & 0.09 \\
\hline fenofibrate & Daphnia. magna & cladoceran & reproduction & Garric et al. 2006 & 50 & 140 & & & $<18$ & $<0.13$ \\
\hline paroxetine & Ceriodaphnia. dubia & cladoceran & reproduction & Garric et al. 2006 & 50 & 600 & & 4 & & $6.6710-3$ \\
\hline fluvoxamine & Ceriodaphnia. dubia & cladoceran & reproduction & Henry et al. 2004 & 50 & 7400 & 26 & & & $3.510-3$ \\
\hline citalopram & Ceriodaphnia. dubia & cladoceran & reproduction & Henry et al. 2003 & 100 & 8000 & & 32 & & $410-3$ \\
\hline ibuprofen & Daphnia.magna & cladoceran & reproduction & Han et al. 2006 & 100 & 2. $10^{5}$ & & & 55 & $2.710-4$ \\
\hline trimethoprim & S. capricornutum & chlorophyceae & growth & Eguchi et al. 2004 & 100 & $2,55 \cdot 10^{5}$ & & & 19 & $7.4510-5$ \\
\hline acebutolol & Ceriodaphnia dubia & cladoceran & reproduction & Garric et al. 2006 & 50 & $1,25 \cdot 10^{6}$ & NA & NA & NA & NA \\
\hline erythromycin & S. capricornutum & chlorophyceae & growth & Eguchi et al. 2004 & 50 & 206 & NA & NA & NA & NA \\
\hline clofibric acid & Ceriodaphnia dubia & cladoceran & reproduction & Ferrari et al. 2004 & $10 *$ & 64 & negligible & negligible & negligible & negligible \\
\hline clofibrate & Daphnia.magna & cladoceran & reproduction & Köpf 1995 *** & 50 & 200 & negligible & negligible & negligible & negligible \\
\hline
\end{tabular}

AF: Assessment Factor.

Taxa species and references refer to the assay that showed the lowest NOEC

* Indicates that risk quotients for these compounds were calculated applying the EMEA methodology (three NOEC values from three different taxonomic groups). Other risk ratios were conducted using TGD (2003) recommendations (with only one or two NOEC values). When three NOEC values for three different taxonomic groups were available, a factor of 10 was applied to the lowest NOEC value; when two NOECs were available, a factor of 50 was applied; a factor of 100 was applied when only one NOEC value was available.

** Quoted by Webb 2001, in Kummerer 2001

ND: not determined. 


\section{References}

AFSSAPS 2006. Agence Française de Sécurité Sanitaire des Produits de Santé. Personal communication.

Andreozzi R., Raffaele M., Nicklas P. 2003. Pharmaceuticals in STP effluents and their solar photodegradation in aquatic environment. Chemosphere 50, pp 319-1330.

Andreozzi R, Caprio V, Ciniglia C, De Champdore M, Lo Giudice R, Marotta R, Zuccato E. 2004. Antibiotics in the environment: Occurrence in Italian STPs, fate, and preliminary assessment on algal toxicity of amoxicillin. Environmental Science and Technology 38, pp 6832-6838.

Ashton D, Hilton M, Thomas KV. 2004. Investigating the environmental transport of human pharmaceuticals to streams in the United Kingdom. Science of theTotal Environment 333, pp 167184.

BCB 2006. Banque Claude Bernard. Available at http://www.resip.fr.

BIAM 2006. Banque de données automatisée sur les médicaments. http://www.biam2.org.

Bendz D, Paxeus NA, Ginn TR, Loge FJ. 2005. Occurrence and fate of pharmaceutically active compounds in the environment, a case study: Höje River in Sweden. Journal oh Hazardous Materials 122, pp 195-204.

Bindschedler M, Degen M, Flesch G, de Gasparo M, Preiswerk G. 1997. Pharmacokinetic and pharmacodynamic interaction of single oral doses of valsartan and furosemide. European Journal of Clinical Pharmacology 52, pp 371-378.

Bound JP, Voulvoulis N. 2006. Predicted and measured concentrations for selected pharmaceuticals in UK rivers: Implications for risk assessment. Water Researh 40, pp 2885-2892.

Bound JP, Voulvoulis N. 2004. Pharmaceuticals in the aquatic environment--a comparison of risk assessment strategies. Chemosphere 56, pp 1143-1155.

Brain RA, Johnson DJ, Richards SM, Hanson ML, Sanderson H, Lam MW, Young C, Mabury SA, Sibley PK, Solomon KR. 2004. Microcosm evaluation of the effects of an eight pharmaceutical mixture to the aquatic macrophytes Lemna gibba and Myriophyllum sibiricum. Aquatic Toxicolology 70, pp 23-40.

Carballa M, Omil F, Lema JM, Llompart M, Garcia C, Rodriguez I, Gomez M, Ternes T. 2005. Behaviour of pharmaceuticals and personal care products in a sewage treatment plant of northwest Spain. Water Science and Technology 52, pp 29-35.

Carlsson C., Johansson A.-K., Alvan G., Bergman K., Kühler T. 2006. Are pharmaceuticals potent environmental pollutants?. Part I: Environmental risk assessments of selected active pharmaceutical ingredients. Science of the Total Environment 364, pp 67-87.

Castiglioni S., Bagnati R., Fanelli R., Pomati F., Calamari D., Zuccato, E. 2006. Removal of pharmaceuticals in sewage treatment plants in Italy. Environmental Science and Technology 40, pp 357-363. 
Chang H., Hu J., Shao B. 2007. Occurrence of natural and synthetic glucocorticoids in sewage treatment plants and receiving river waters. Environmental Science and Technology 41, pp 3462-3468.

Christensen AM, Faaborg-Andersen S, Ingerslev F, Baun A. 2007. Mixture and single-substance toxicity of selective serotonin reuptake inhibitors toward algae and crustaceans. Environ Toxicology and Chemistry 26, pp 85-91.

Clara M, Strenn B, Gans O, Martinez E, Kreuzinger N, Kroiss H. 2005. Removal of selected pharmaceuticals, fragrances and endocrine disrupting compounds in a membrane bioreactor and conventional wastewater treatment plants. Water Research 39, pp 4797-4807.

Cleuvers M. 2003. Initial risk assessment for three $\beta$-blockers found in the aquatic environment. Chemosphere 59, pp 199-205.

D'Ascenzo G, Di Corcia A, Gentili A, Mancini R, Mastropasqua R, Nazzari M, Samperi R. 2003. Fate of natural estrogen conjugates in municipal sewage transport and treatment facilities. Science of the Total Environment 302, pp 199-209.

Daughton CG, Ternes TA. 1999. Pharmaceuticals and personal care products in the environment: Agents of subtle change? Environmental Health Perspectives 107, pp 907-938.

DellaGreca M, Fiorentino A, Isidori M, Lavorgna M, Previtera L, Rubino M, Temussi F. 2004. Toxicity of prednisolone, dexamethasone and their photochemical derivatives on aquatic organisms. Chemosphere 54, pp 629-637.

Dorosz. Guide Pratique des Médicaments. 2002. 22 Ed. Maloine editions.

DREES 2006. Direction de la recherche des études de l'évaluation et des statistiques. Les ventes de médicaments remboursables en 2005. Clerc ME. Etudes et résultats 508.

Drugdex@ 2006. Thomson Micromedex@. Healthcare series vol. 129 and 130. http:www. micromedex.com/products/drugdex/

Drugs.com 2006. Prescription Drug Information, Side Effects, Interactions. Available at http://www.Drugs.com.

Dulin R., Silberstein N., Bonnin M., Saux MC. 2002. Comparison and practical guidelines of selective serotonin reuptake inhibitors [Comparaison et critères de choix des inhibiteurs sélectifs de la recapture de la sérotonine]. Journal de Pharmacie Clinique 21, pp 39-46.

Dzialowski E.M., Turner P.K., Brooks B.W. 2006. Physiological and reproductive effects of beta adrenergic receptor antagonists in Daphnia magna. Archives Environ Contam Toxicology 50, pp 503-510

Eguchi K, Nagase H, Ozawa M, Endoh YS, Goto K, Hirata K, Miyamoto K,Yoshimura H. 2004. Evaluation of antimicrobial agents for veterinary use in the ecotoxicity test using microalgae. Chemosphere 57, pp 1733-1738.

EMEA 2006. European Medicine Agency guideline on the environmental risk assessment of medicinal products for human use. EMEA/CHMP/SWP/4447/00. 
Endicoot JA, Ling V. 1989. The biochemistry of P-glycoprotein-mediated multidrug resistance. Annual Review of Biochemistry 58, pp 137-171.

Escher BI, Bramaz N, Richter M, Lienert J. 2006. Comparative ecotoxicological hazard assessment of beta-blockers and their human metabolites using a mode-of-action-based test battery and a QSAR approach. Environmental Science and Technology 40, pp 7402-7408.

Fent K, Weston AA, Caminada D. 2006. Ecotoxicology of human pharmaceuticals. Aquatic Toxicology 76, pp 122-159.

Ferrari B, Mons R, Vollat B, Fraysse B, Paxéus N, Lo Giudice R, Pollio A, Garric J. 2004. Environmental risk assessment of six human pharmaceuticals: Are the current environmental risk assessment procedures sufficient for the protection of the aquatic environment? Environmental Toxicology and Chemistry 23, pp 1344-1354.

FDA-CDER 1996. Retrospective review of ecotoxicity data submitted in environmental assessments. FDA center for Drug Evaluation and Research, Rockville, MD, USA (Docket No. 96N-0057).

Fraysse B, Garric J. 2005. Prediction and experimental validation of acute toxicity of B-blockers in Ceriodaphnia dubia. Environmental Toxicology and Chemistry 24, pp 2470-2476.

Garric J, Ferrari B, Fraysse B, Mons R, Vollat B. 2006. Impact de médicaments à usage humain sur les organismes aquatiques d'eau douce. Environnement Risques et Santé 5, pp 290-295.

Halling-Sorensen B, Nors Nielsen S, Lanzky PF, Ingerslev F, Holten-Lutzhoft HC, Jorgensen SE. 1998. Occurrence, fate and effects of pharmaceutical substances in the environment- A review. Chemosphere 36, pp 357-393.

Han GH, Hur HG, Kim SD. 2006. Ecotoxicological risk of pharmaceuticals from wastewater treatment plants in Korea: Occurrence and toxicity to Daphnia magna. Environmental Toxicology and Chemistry 25, pp 265-271.

Hardman JG, Limbird LE, Molinoff PS, Ruddon RW, Goodman AG. (eds). 1996. Goodman and Gilman's The Pharmacological Basis of Therapeutics. 9th edition New York, NY: McGraw-Hill Professional.

Henry TB, Kwon JW, Armbrust KL, Black MC. 2004. Acute and chronic toxicity of five selective serotonin reuptake inhibitors in Ceriodaphnia dubia. Environmental Toxicology and Chemistry 23, pp 2229-2233.

Hirsch R, Ternes T, Haberer K, Kratz KL. 1999. Occurrence of antibiotics in the aquatic environment. Science of the Total Environment 225, pp 109-118.

Holten-Lützhøft HC, Halling-Sørensen B, and Jørgensen SE. 1999. Algal toxicity of antibacterial agents applied in Danish fish farming. Archives of Environmental Contamination and Toxicology 36, pp $1-6$.

HSDB, Hazardous Substances Databank. available at http://toxnet.nlm.nih.gov. 
Huggett D.B., Cook J.C., Ericson J.F., Williams R.T. 2003. A theoretical model for utilizing mammalian pharmacology and safety data to prioritize potential impacts of human pharmaceuticals to fish. Humand and Ecological Risk Assessment 9, pp 1789-1799.

Huggett D.B., Brooks B.W., Peterson B., Foran C.M., Schlenk D. 2002. Toxicity of select beta adrenergic receptor-blocking pharmaceuticals (B-blockers) on aquatic organisms. Archives of Environmental Contamination and Toxicology 43, pp 229-235.

Huschek G., Hansen P.D., Maurer H.H., Krengel D., Kayser A. 2004. Environmental risk assessment of medicinal products for human use according to European Commission recommendations. Environmental Toxicology 19, pp 226-240.

Hyttel J. 1996. Comparative pharmacology of selective serotonin re-uptake inhibitors (SSRIs). Nordisk Journal of Psychiatry 47, pp 5-12.

Isidori M, Nardelli A, Parrella A, Pascarella L, Previtera L. 2006. A multispecies study to assess the toxic and genotoxic effect of pharmaceuticals: Furosemide and its photoproduct. Chemosphere 63, pp 785-793.

Isidori M, Lavorgna M, Nardelli A, Parrella A, Previtera L, Rubino M. 2005. Ecotoxicity of naproxen and its phototransformation products. Science of Total Environment 348, pp 93-101.

Jjemba PK. 2006. Excretion and ecotoxicity of pharmaceutical and personal care products in the environment. Ecotoxicological and Environmental Safety 63, pp 113-130.

Jones OAH, Voulvoulis N, Lester JN. 2002. Aquatic environmental assessment of the top 25 English prescription pharmaceuticals. Water Research 36, pp 5013-5022.

Kolpin DW, Furlong ET, Meyer MT, Thurman EM, Zaugg SD, Barber LB, Buxton HT. 2002. Pharmaceuticals, hormones, and other organic wastewater contaminants in U.S. streams, 19992000: A national reconnaissance. Environmental Science and Technology 36, pp 1202-1211.

Köpf W. 1995. Effects of endocrine substances in bioassays with aquatic organisms. Presentation at the $50^{\text {th }}$ seminar of the Bavarian Association for Water Supply. Substances with endocrine effect in water. (Quoted in Webb 2001).

Kümmerer K. 2001. Pharmaceuticals in the environment : Sources, fate, effects and risks. Klaus Kümmerer Editor. Springer-Verlag Berlin Heidelberg New York.

Kümmerer K, 2000. Drugs, diagnostic agents and disinfectants in wastewater and water--a review. Schriftenreihe des Vereins fur Wasser-, Boden- und Lufthygiene 105: 59-71.

Lange R, Dietrich D. 2002. Environmental risk assessment of pharmaceutical drug substances-conceptual considerations. Toxicology Letters 131, pp 97-104.

Langston WJ, Burt GR, Chesman BS, Vane CH. 2005. Partitioning, bioavailability and effects of oestrogens and xeno-oestrogens in the aquatic environment. J Mar Biol Assoc UK. 85, pp 1-31.

Liebig M, Moltmann JF, Knacker T. 2006. Evaluation of measured and predicted environmental concentrations of selected human pharmaceuticals and personal care products. Environmental Science \& Pollution Research 13, pp 110-119. 
Lienert J, Güdel K, Escher BI. 2007. Screening method for ecotoxicological hazard assessment of 42 pharmaceuticals considering human metabolism and excretory routes. Environmental Science and Technolpgy 41, pp 4471-4478.

Lynn RK, Smith RG, Thompson RM, Deinzer ML, Griffin D, Gerber N. 1978. Characterization of glucuronide metabolites of carbamazepine in human urine by gas chromatography and mass spectrometry. Drug Metabolism and Disposition 6, pp 494-501.

Marques CR, Abrantes N, Goncalves F. 2004. Life-history traits of standard and autochthonous cladocerans: I. Acute and chronic effects of acetylsalicylic acid. Environmental Toxicology 19, pp 518-526.

Martindale. The complete drug reference. 2002. 33 Ed. Sean C Sweetman Ed. Pharmaceutical Press. Great Britain.

Merck, 2001. The Merck Index, $13^{\text {th }}$ ed. London: Merck Publications.

Miège C, Favier M, Brosse C, Canler JP, Coquery M. 2006. Occurrence of betablockers in effluents of wastewater treatment plants from the Lyon area (France) and risk assessment for the downstream rivers. Talanta 70, pp 739-744.

Mills LJ, Chichester C. 2005. Review of evidence: Are endocrine-disrupting chemicals in the aquatic environment impacting fish populations? Science of the Total Environment 343, pp 1-34.

Oaks JL, Gilbert M, Virani MZ, Watson RT, Meteyer CU, Rideout BA, Shivaprasad HL, Ahmed S, Chaudhry MJI, Arshad M, Mahmood S, Ali A, Khan AA. 2004. Diclofenac residues as the cause of vulture population decline in Pakistan. Nature 427, pp 630-633.

Paffoni C., Welte B., Gousailles M., Montiel A. 2006. New molecules involved by the European directives: From wastewater to drinking water treatment plants [Nouvelles molécules mises en cause par les directives européennes: De la station d'épuration à l'usine de traitement d'eau potable]. Journal Européen d'Hydrologie 37, pp 21-38.

Paxéus N. 2004. Removal of selected non-steroidal anti-inflammatory drugs (NSAIDs), gemfibrozil, carbamazepine, $\beta$-blockers, trimethoprim and triclosan in conventional wastewater treatment plants in five EU countries and their discharge to the aquatic environment. Water Science and Technology 50, pp 253-260.

PNSE 2004. Plan National Santé Environnement. Ministère de la Santé et de la Protection sociale. Ministère de l'Écologie et du Développement durable. Ministère de l'Emploi, du Travail et de la Cohésion sociale. Ministère délégué à la Recherche. Available at www.sante.gouv.fr/htm/dossiers/pnse/rapport.pdf.

Qin-Tao L, Williams HE. 2007. Kinetics and degradation products for direct photolysis of $\beta$-blockers in water. Environmental Science and Technology 41, pp 803-810.

Rabiet M, Togola A, Brissaud F, Seidel JL, Budzinski H, Elbaz-Poulichet F. 2006. Consequences of treated water recycling as regards pharmaceuticals and drugs in surface and ground waters of a medium-sized mediterranean catchment. Environmental Science and Technology 40, pp 52825288. 
Richards SM, Wilson CJ, Johnson DJ, Castle DM, Lam M, Mabury SA, Sibley PK, Solomon KR. 2004. Effects of pharmaceutical mixtures in aquatic microcosms. Environmental Toxicology and Chemistry 23, pp 1035-1042.

Schorderet M. 1998. Pharmacologie : Des concepts fondamentaux aux applications therapeutiques" 3rd Ed. Frison roche. France.

Schwaiger J, Ferling H, Mallow U, Wintermayr H, Negele RD. 2004. Toxic effects of the non-steroidal anti-inflammatory drug diclofenac. Part I: Histopathological alterations and bioaccumulation in rainbow trout. Aquatic Toxicology 68, pp 141-150.

Seiler JP. 2002. Pharmacodynamic activity of drugs and ecotoxicology--can the two be connected? Toxicology Letters 131, pp 105-115.

Stumpf M, Ternes TA, Wilken RD, Rodriguez SV, Baumann W. 1999. Polar drug residues in sewage and natural waters in the state of Rio de Janeiro, Brazil. Science of the Total Environment 225, pp $135-141$.

Ternes TA. 1998. Occurrence of drugs in German sewage treatment plants and rivers. Water Research 32, pp 3245-3260.

Ternes TA, Kreckel P, Mueller J. 1999. Behaviour and occurrence of estrogens in municipal sewage treatment plants - II. Aerobic batch experiments with activated sludge. Science of the Total Environment 225, pp 91-99.

TGD 2003. Technical Guidance Document on risk Assessment. TGD part II. European Commission joint research centre. EUR $20418 \mathrm{EN} / 2$.

Togola A, Bristeau S, and Amalric L. 2007. Occurence of pharmaceuticals in aquatic systems of LoireBritlang Basin (France). Poster communication. ERAPharm International Conference on Pharmaceuticals in the Environment. Lakeside Conference Center, York, UK

Toomey BH, Epel D. 1993. Multixenobiotic resistance in Urechis caupo embryos: protection from environmental toxins. Biol Bull 185: 355-364.Triebskorn R, Casper H, Heyd A, Eikemper R, Köhler HR, Schwaiger J. 2004. Toxic effects of the non-steroidal anti-inflammatory drug diclofenac: Part II. Cytological effects in liver, kidney, gills and intestine of rainbow trout (Oncorhynchus mykiss). Aquatic Toxicology 68, pp 151-166.

Triebskorn R, Casper H, Heyd A, et al. 2004. Toxic effects of the non-steroidal anti-inflammatory drug diclofenac: Part II. Cytological effects in liver, kidney, gills and intestine of rainbow trout (Oncorhynchus mykiss). Aquatic Toxicology 68, pp151-66.

Waggott A. 1981. Trace Organic Substances in the River Lee in Cooper, W.J. (ed.) Chemistry in Water Reuse. Ann. Arbor Publishers Inc. pp 55-99.

Webb SF. 2001. A data based perspective on the environmental risk assessment of human pharmaceuticals. Collation of available ecotoxicity data. in Kümmerer 2001. Pharmaceuticals in the environment : Sources, fate, effects and risks. Chapter 17 pp221-230. Klaus Kümmerer Editor. Springer-Verlag Berlin Heidelberg New York. 
Williams M, Saison CLA, Williams DB, Kookana RS. 2006. Can aquatic distribution of human pharmaceuticals be related to pharmacological data? Chemosphere 65, pp 2253-2259.

Yamashita N, Yasojima M, Nakada N, Miyajima K, Komori K, Suzuki Y, Tanaka H. 2006. Effects of antibacterial agents, levofloxacin and clarithromycin, on aquatic organisms Water Science and Technology 53, pp 65-72.

Zuccato E, Castiglioni S, Fanelli R. 2005. Identification of the pharmaceuticals for human use contaminating the Italian aquatic environment. Journal of Hazardous Materials 122, pp 205-209. 